Majda Bojić

DOI: $10.4312 / v h \cdot 24.1 .169-184$

Universidade de Zagreb

(c) (1) ()

\title{
Milton Hatoum, intertextualidade e memória da literatura
}

Palavras-chave: Milton Hatoum, intertextualidade, memória, recordação, memória da literatura

\section{Introdução}

O estudo do conjunto da obra do escritor brasileiro Milton Hatoum revela uma relação intrínseca com a memória. A concretização literária desta relação evidencia-se em níveis diferentes - as suas obras tematizam e problematizam o fenômeno e o papel da memória enquanto que a própria estrutura narrativa da ficção hatoumiana se realiza como o resultado da recordação, necessária para a reconstrução da história pessoal e familiar. No entanto, encontramos na obra deste escritor amazonense, mais um fenômeno que pode ser considerado em relação à memória: a intertextualidade. O objetivo do nosso artigo será, portanto, investigar esse dispositivo literário partindo da sua relação com a memória. Para tal fim, principiamos com o argumento da teórica alemã Renate Lachmann que oferece uma visão particular sobre a relação entre memória, literatura e intertextualidade. O texto literário, segundo ela, possui a sua própria memória na forma das relações intertextuais (Lachmann, 2004: 304). A partir desta perspectiva e do estudo da intertextualidade na obra de Milton Hatoum, pretendemos ressaltar nela o papel dessa «memória da literatura», acrescentando assim mais um elemento que completa o tecido mnémico hatoumiano.

\section{Intertextualidade - memória da literatura}

Para a estipulação do termo «memória da literatura», e o seu uso dentro de estudos de memória, foi importante o trabalho de Renate Lachmann, que 
considerou os textos como possuidores de memória própria: «a memória do texto é formada pela intertextualidade das suas referências» (Lachmann, 2010: 304). A criação e o uso da expressão de «memória da literatura», expliquemos, reside no uso metafórico do termo já que, como observa Astrid Erll (2011: 70), outra teórica alemã relevante para estudos sobre memória, os textos literários de fato não possuem a capacidade de recordação.

Nas palavras de Lachmann (2004: 173), escrever «é um ato de memória e também uma nova interpretação, pela qual cada texto novo é gravado no espaço de memória.» As referências intertextuais, segundo ela, podem dizer respeito a diferentes elementos do «outro» texto, como seu gênero, recursos estilísticos, motivos ou técnicas narrativas. Mediante essas referências, o texto novo interpreta e transforma os textos antigos e inscreve-se num espaço de memória já criado pelos textos anteriores (Lachmann 2004: 172)ํ․‥

Outra teórica que concebe a intertextualidade enquanto memória da literatura é Tiphaine Samoyault. O que é intertextualidade, «senão a memória que a literatura tem de si mesma?", pergunta a pesquisadora francêsa (Samoyault, 2008: 10). «A literatura», acrescenta Samoyault (2008: 47),

se escreve com a lembrança daquilo que é, daquilo que foi. Ela a exprime, movimentando sua memória e a inscrevendo nos textos por meio de um certo número de procedimentos de retomadas, de lembranças e de re-escrituras, cujo trabalho faz aparecer o intertexto. Ela mostra assim sua capacidade de se constituir em suma ou em bibliotéca e de sugerir o imaginário que ela própria tem de $\mathrm{si}^{2}$.

1 Acrescenta-se aqui a distinção de Astrid Erll (2011: 70) entre dois aspectos da expressão «memória da literatura» - o primeiro, que compreende o uso do termo enquanto genitivus subjectivus, onde a literatura é vista como um sistema simbólico capaz de lembrar de si mesmo através da intertextualidade («os textos anteriores são lembrados através das referências intertextuais») e o outro, onde o termo é entendido enquanto genus objectivus, onde a literatura é enxergada enquanto sistema social. Neste caso, as obras de literatura são «lembradas» através de histórias de literatura e de formações de canones. Enfim, os conceitos que dizem respeito a uma «memória da literatura», segundo Erll (2011: 70), são «baseados na suposição de que a literatura só pode ser corretamente compreendida quando enxergada do ponto de vista da sua dinâmica diacrónica.»

2 Samoyault (2008: 68) acrescenta o argumento semelhante mais tarde no texto: «As práticas intertextuais informam sobre o funcionamento da memória que uma época, um grupo, um indivíduo têm das obras que os precederam ou que lhes são contemporâneas. Elas exprimem ao mesmo tempo o peso desta memória, a dificuldade de um gesto que se sabe suceder a outro e vir sempre depois.» 
Nesse sentido, acreditamos que a «capacidade» da qual fala Samoyault seja proveituosa para designar um dos objetivos do nosso trabalho, sendo ele o de esboçar essa «bibliotéca» e o «imaginário» livresco contido nas narrativas de Milton Hatoum.

Partindo dessas conceções, sempre interessados em aspectos de memória, investigaremos as relações intertextuais que aparecem na obra de Milton Hatoum. Daremos enfoque às relações de intertextualidade literária, deixando de lado as implicações socioculturais extraliterárias. Também, os intertextos que pretendemos estudar, são intertextos que fazem parte da literatura em sentido lato do termo, incluindo referências à Bíblia ou ao Mito do Eldorado.

Dentro da prosa hatoumiana, a dimensão intertextual compreende a existência de relações complexas e de variada ordem. Como indicamos atrás, os textos de Milton Hatoum evidenciam referências aos discursos literários de proveniência brasileira e estrangeira como também aquelas que dizem respeito aos textos literários do próprio autor. Estabelece-se, portanto, uma distinção inicial entre as relações que dizem respeito à intertextualidade homo-autoral e aquelas relativas à intertextualidade hetero-autoral, ou seja, aquelas que se estabelecem respetivamente a partir do diálogo entre as próprias obras da autoria de Hatoum e outras onde se criam relações com textos de autoria alheia.

Antes da nossa análise, gostaríamos apenas de chamar a atenção para o fato de que a nossa análise intertextual se explica pelo desejo de examinar essa intertextualidade à luz da memória enquanto conceito estrutural da obra hatoumiana. Por isso não faremos levantamento mais profundo de relações intertextuais que a obra de Hatoum possa conter, pois não é este o propósito do nosso trabalho.

\section{Intertextualidade hetero-autoral}

«Entretecida pelo diálogo de vários textos, de várias vozes e consciências», a intertextualidade é -«na sua dinâmica originária e essencial»- betero-autoral (Aguiar e Silva, 2011: 630). O conceito se refere às relações intertextuais entre os textos de diferentes autores. Começamos com a análise da intertextualidade betero-autoral porque as estipulações de memória da literatura se referem maiormente a ela. Também, principiamos aqui porque se trata de uma intertextualidade par exellence, já que nos inícios da estipulação do termo um dos seus maiores impactos era questionar a ideia do isolamento do texto e, por consequência, a questão da originalidade, colocando em causa os domínios e limites da obra do próprio autor. 
Apresentaremos agora alguns exemplos desse tipo de intertextualidade com referência à obra estudada. Por causa das limitações impostas pelo escopo e o tamanho do nosso trabalho, pretendemos abordar só os intertextos mais importantes para a interpretação.

Publicado em 1989, Relato de um certo Oriente é o romance de estréia de Milton Hatoum. Conta a história de uma figura feminina que volta, após anos de ausência, à Manaus, cidade da sua infância. O contato repentino com o espaço e o universo do seu passado, provoca nela uma efusão de lembranças. Os relatos desta narradora não-nomeada recriam um mundo marcado pela convivência de culturas diferentes. Ela pertence à família de imigrantes libaneses que tenta construir uma vida nova passando por desafios e transformações culturais. O romance possui uma estrutura complexa - para construir o seu relato, a narradora recorre aos discursos relatados por narradores diferentes: Hakim, seu tio; o fotógrafo alemão Dorner, amigo da família; o marido de Emilie; mãe adotiva da narradora principal e Hindié Conceição, empregada e amiga dela. Todos eles contam histórias - memórias dos momentos marcantes da vida da família. Elabora-se assim um relato que flutua no entrecruzamento de vozes diferentes que criam o universo do passado da narradora principal.

A intertextualidade que logo se impõe em relação ao romance Relato de um certo Oriente, diz respeito à obra As mil e uma noites. A relação é referida explicitamente, e muitas vezes, como no exemplo seguinte quando Dorner, amigo do pai da narradora, revela a curiosa semelhança entre as histórias que o pai de Hakim contava e o livro As mil e uma noites. Assim, Dorner diz à narradora:

O convívio com teu pai me instigou a ler As mil e uma noites, na tradução de Henning. A leitura cuidadosa e morosa desse livro tornou nossa amizade mais íntima; por muito tempo acreditei no que ele me contava, mas aos poucos constatei que havia uma certa alusão àquele livro, e que os episódios de sua vida eram transcrições adulteradas de algumas noites, como se a voz da narradora ecoasse na fala do meu amigo. (Hatoum, 2008: 71)

Percebendo que as lembranças do pai foram influenciadas pela leitura do livro, Dorner estaria fazendo referência à literatura que (enquanto sistema simbólico) passa a fazer parte das memória individuais. Como Dorner constata na continuação: «afinal, o tempo acaba borrando as diferenças entre uma vida e um livro.» (Hatoum, 2008: 71) 
O intertexto de As mil e uma noites está também presente enquanto alusão implícita. Pensamos principalmente na estrutura de encaixes contendo histórias nunca acabadas e na narradora principal feminina. Na recepção crítica do romance, às vezes a sua estrutura é comparada à estrutura do livro As mil e uma noites, e o próprio autor se manifesta acerca disso:

Acho que minha literatura foi mais influenciada por Machado de Assis, por William Faulkner. Dos árabes, as Mil e Uma Noites. A estrutura do Relato lembra um pouco a das histórias que puxam histórias de As Mil e Uma Noites, que, enfim é um livro lido e apreciado por todos os grandes escritores do Ocidente. ${ }^{3}$

Em entrevista concedida a Aida Hanania, Hatoum também desvela essa referência:

Ainda quanto a aspectos estruturais, devo dizer que pensei muito na estrutura das Mile Uma Noites; pensei numa narradora, numa personagem feminina que contasse essa história... E isso, por várias razões - por razões de ordem meta-lingüística, a referência a Sheharzade; e também pelo fato de a mulher na família árabe ser submissa (aparentemente...), mas, ao mesmo tempo, ser a detentora do segredo, de certos segredos da família... ${ }^{4}$

A alusão implícita à obra árabe é evidenciada ainda num episódio da trama do romance, quando a empregada Anastácia repete o modelo da narradora das Mil e Uma Noites ao contar histórias «para se poupar». Porém, no romance de Hatoum o intertexto está transformado. Enquanto a narradora das Mil e Uma Noites conta histórias para se salvar da ameaça de morte, Anastácia o faz para escapar ao trabalho árduo em casa de Emilie:

[...] Anastácia, através da voz que evocava vivência e imaginação, procurava um repouso, uma trégua ao árduo trabalho a que se dedicava. Ao contar histórias, sua vida parava para respirar; e aquela voz trazia para dentro do sobrado, para dentro de mim e de Emilie, visões de um mundo misterioso: não exatamente

3 Hatoum, M. O arquiteto da memória. Entrevista concedida a Soraia Vilela: http://www. dw.com/pt/o-arquiteto-da-mem\%C3\%B3ria/a-1355392 (1-3-2016).

4 Hatoum, M. Entrevista concedida a Aida Hanania: http://hottopos.com/collat6/milton1. htm (20-3-2016). 
o da floresta, mas o do imaginário de uma mulher que falava para se poupar, que inventava para tentar escapar ao esforço físico, como se a fala permitisse a suspensão momentânea do martírio. Emilie deixava-a falar, mas por vezes seu rosto interrogava o significado de um termo qualquer de origem indígena, ou de uma expressão não utilizada na cidade, e que pertencia à vida da lavadeira, a um tempo remotíssimo, a um lugar esquecido à margem de um rio, e que desconhecíamos. (Hatoum, 2008: 82)

Anastácia recorre à imaginação e aos meandros da sua memória para transmitir a Emilie histórias que evocam a cultura dos indígenas. Assim como Sheharzade, Anastácia, é uma figura que conta histórias à sua patroa «para se poupar». Mas, desta vez, encontramo-nos dentro do espaço amazónico, onde a vinda de imigrantes libaneses traz desafios novos para a construção da comunidade local. Anastácia, empregada de Emilie, conta histórias para adiar o momento de trabalho árduo enquanto que o conteúdo do seu discurso revela (e ensina) elementos da sua cultura.

$\mathrm{Na}$ posição central do enredo do segundo romance de Milton Hatoum, Dois irmãos (2000), encontra-se a relação conflituosa entre dois irmãos gêmeos, Omar e Yakub - uma relação cheia de atritos e rivalidades. A história dos irmãos é contada por Nael - filho de Domingas, empregada da família, que tenta descobrir quem é o seu pai.

A obra logo começa com versos do poeta brasileiro Carlos Drummond de Andrade: «A casa foi vendida com todas as lembranças/todos os móveis todos os pesadelos/todos os pecados cometidos ou em vias de cometer/a casa foi vendida com seu bater de portas/com seu vento encanado sua vista do mundo/seus imponderáveis [...]» (Hatoum, 2006: 7)

Esta epígrafe como que anuncia, a respeito do romance de Hatoum, o lugar temático central de família, de lembrança e da casa como espaço privilegiado da memória.

Mas o intertexto que engloba o enredo do romance e os seus personagens é o intertexto bíblico. A relação entre os dois irmãos (a posição central da relação está implícita no próprio título) é intertextualmente carregada de contexto bíblico. Assim, as referências bíblicas encontram-se evocadas no texto de modo explícito. No momento seguinte do texto revela-se a ansiedade da mãe dos gêmeos perante a relação conflituosa entre os seus filhos: 
«Não queria morrer vendo os gêmeos se odiarem como dois inimigos. Não era mãe de Caim e Abel. Ninguém havia conseguido apaziguá-los, nem Halim, nem as orações, nem mesmo Deus.» (Hatoum, 2006: 170-171) E ainda, referindo-se à desavença entre ele e Omar, Yakub envia uma carta para sua mãe com um comentário que deixa a mãe preocupada: «Oxalá seja resolvido com civilidade; se houver violência, será uma cena bíblica.» (Hatoum, 2006: 171)

A relação intertextual com a Bíblia também se efetua mediante uma alusão implícita. Refere-se principalmente à relação conflituosa dos dois irmãos. Além do já evocado episódio bíblico de Caim e Abel, o texto de Hatoum dialoga com a história dos irmãos gêmeos Esaú e Jacó, referência intertextual presente já no texto do maior romancista do realismo brasileiro, Machado de Assis. 5 A referência que remete ao Gênesis, livro inicial da Bíblia, evidencia-se de modo implícito. Além da presença de congruências no enredo dos dois textos, como a preferência da mãe pelo caçula (Omar/Jacó), é sobretudo a alusão à dinâmica de rivalidade entre os irmãos que paira sobre o romance inteiro criando uma atmosfera de inimizade arcáica e reforçando a ideia da paz impossível. Por se tratar de um diálogo com uma história antiga, a rivalidade aparece como que enfatizada e evoca uma impressão da eternidade.

A novela Órfãos do Eldorado (2008) traz a história de Arminto Cordovil que, narrando a um interlocutor desconhecido, relata os fatos mais marcantes do seu passado: a relação difícil com seu pai que o culpa pela morte da mãe, a falência da empresa da família e o amor impossível pela índia-órfã, Dinaura. Esta novela foi escrita depois de ter sido encomendada por parte de uma editora escocesa (Canongate) para integrar a coleção Myths querendo publicar textos de autores contemporâneos baseados na reescrita de mitos antigos. Portanto, o texto de Hatoum está impregnado pela ideia da releitura do mito do Eldorado que revela a existência de uma cidade encantada submersa no fundo do rio, cidade de opulência e riqueza. Dialogando com o mito, a novela faz uma releitura irônica do mito. Em vez da riqueza anunciada pelo título, o enredo está repleto de ruínas, desilusão e perda.

O mito faz parte do enredo desde início. Assim conhecemos que Arminto, ainda na sua infância, conheceu o mito amazônico da Cidade Encantada por parte de Florita, personagem indígena que o criou. $\mathrm{O}$ mito elabora a crença de que:

5 Trata-se do romance Esaú e Jacó, de Machado Assis, publicado em 1904. 
no fundo de um rio ou lago existe uma cidade rica, esplêndida, exemplo de harmonia e justiça social, onde as pessoas vivem como seres encantados. Elas são seduzidas e levadas para o fundo do rio por seres das águas ou da floresta (geralmente um boto ou uma cobra sucuri), e só voltam ao nosso mundo com a intermediação de um pajé, cujo corpo ou espírito tem o poder de viajar para a Cidade Encantada, conversar com seus moradores e, eventualmente, trazê-los de volta ao nosso mundo. (Hatoum, 2008: 105-106)

A relação entre o mito de Cidade Encantada e o do Eldorado é explicado pelo narrador do «Posfácio» no fim do livro:

Anos depois, ao ler os relatos de conquistadores e viajantes europeus sobre Amazônia, percebi que o mito do Eldorado era uma das versões ou variações possíveis da Cidade Encantada, que, na Amazônia, é referida também como uma lenda. Mitos que fazem parte da cultura indo-européia, mas também da ameríndia e de muitas outras. Porque os mitos, assim como as culturas, viajam e estão entrelaçados. Pertencem à História e à memória coletiva. (Hatoum, 2008: 106)

Assim como consta na citação, os mitos «viajam», são memorizados e fazem parte de culturas e de suas histórias. Logo no início da novela, Arminto revela que a sua infância foi marcada por histórias e lendas indígenas fascinantes, assustadoras e inesquecíveis, comentando de que «há um momento em que as histórias fazem parte das nossas vidas». (Hatoum, 2008: 13) De fato, os mitos fazem uma parte importante da história narrada - o protagonista é atormentado pelos mitos. Na infância, ele presencia a cena trágica quando uma índia tapuia se atira na água em busca dum «mundo melhor, sem tanto sofrimento, desgraça». (Hatoum, 2008: 11) Também, mais tarde no texto, a sua paixão, Dinaura, foge depois da noite de amor enquanto a comunidade comenta de que ela teria ido para a Cidade Encantada.

Os mitos constituem um intertexto com o qual um diálogo constante se estabelece, oferecendo uma variante mística na leitura do destino de personagens levadas pelas forças míticas. Porém, no final, os mitos são mitos e Eldorado é mais um barco afundado no rio - em Órfãos do Eldorado o mito do Eldorado é reelaborado de modo irônico. Eldorado é o nome do barco da companhia da família Cordovil que afunda no rio e traz desgraça material à família. A imagem 
da busca pela cidade paradisíaca torna-se uma ilusão frustrada pelos motivos reais: a falência da empresa dos Cordovil, a fuga de Dinaura, o fim da época de prosperidade para a cidade de Manaus. ${ }^{6}$

Depois de termos observado estes exemplos representativos da intertextualidade hetero-autoral em relação à obra hatoumiana, podemos afirmar o seguinte: na obra estudada encontramos diálogos com intertextos referidos de modo explícito, através de citações, da paráfrase e da imitação declarada e de modo implícito por meio de alusões. As transformações do intertexto vão no sentido da sua apropriação ou no sentido da sua negação.

Todas as três obras que analisámos, usam intertextos que podem ser considerados como essenciais para a construção narrativa. Na primeira, Relato de um certo Oriente, o intertexto de As mil e uma noites, além de ser explicitamente referido, evoca e ressalta a importância da figura feminina que constrói uma estrutura complexa de relatos. No segundo romance, Dois irmãos, o intertexto bíblico poderia ser enxergado como central para a narração que propulsiona a história dos dois irmãos. Enfim, o enredo principal da novela Órfãos do Eldorado (o próprio título já parece denotar a posição central do intertexto) é construído como uma releitura do mito do Eldorado «às avessas». Portanto, à luz da leitura da intertextualidade enquanto memória da literatura, podemos constatar que essa memória ocupa um lugar de destaque nas obras de Hatoum - não só pela variedade dos intertextos presentes mas também pelo fato de que os intertextos ocupam um lugar destacado, perpassando a construção semântica das narrativas e atribuindo assim para a coesão interna da obra. ${ }^{7}$

Em seguida, é importante destacar que a dimensão intertextual nas obras de Hatoum faz parte do enredo. O diálogo intertextual não quebra o ritmo da narração ou a ilusão referencial e não destaca a natureza textual da obra. Ademais, a relação entre intertextualidade e memória é tematizada ao nível semântico dos textos onde intertextos passam a fazer parte integrativa da memória das personagens. Assim, no primeiro romance de Hatoum, Dorner repara a curiosa

6 A impossibilidade de fuga para um lugar melhor é anunciada logo no início da novela pela epígrafe de Konstantinos Kaváfis. O intertexto aparece mais umas vezes no texto como alusão e paráfrase.

7 Os intertextos que acabámos de mencionar referem-se a textos relevantes da cultura mundial - o que acrescenta o seu valor semântico e simbólico. Nesse sentido, Aleida Assmann considera haver textos de importância especial para as sociedades - são os chamados «textos culturais» que transmitem o conhecimento sobre a origem cultural, a identidade e os valores do grupo. Através da leitura, o leitor desse texto, «sente que faz parte de uma comunidade mnemônica». (Assmann apud Erll, 2011: 162) 
semelhança entre o livro As mil e uma noites e as histórias contadas pelo marido de Emilie. No segundo romance, de novo encontramos uma referência explícita à literatura como parte da memória individual e coletiva e na novela de Hatoum, como vimos atrás, destaca-se que os mitos fazem parte da memória coletiva. ${ }^{8}$

A partir da análise que fizemos foi possível observar a maneira como o diálogo intertextual presente nas obras de Hatoum invoca o trabalho da memória que reside no resgate do passado literário. Os exemplos que ressaltamos mostraram também o modo como os intertextos fazem parte dum arqui-sistema estético hatoumiano fundamentado com base na memória. Acreditamos, no entanto, que o estudo da intertextualidade hetero-autoral não exaure todas as possibilidades de encontrar uma relação entre a intertextualidade na obra de Hatoum e a memória como o seu princípio estrutural constitutivo. Vemos uma possibilidade de encontrar a conexão entre intertextualidade e memória (conforme o propósito da nossa pesquisa) também no contexto da intertextualidade bomo-autoral.

\section{Intertextualidade homo-autoral}

A intertextualidade bomo-autoral manifesta-se quando os textos de um autor estabelecem relações intertextuais com outros textos do mesmo autor (Aguiar e Silva, 2011: 630). No conjunto da obra de Milton Hatoum, existem várias relações intertextuais entre as próprias obras do autor. Referem-se principalmente à repetição das personagens, narradores e espaços. Assim, nos dois primeiros romances de Hatoum (Relato de um certo Oriente e Dois irmãos) encontramos a mesma personagem de Emilie. Tendo uma posição central no primeiro romance, no segundo ela meramente exerce uma parte secundária. Também, é nestes dois romances que encontramos o casal Benemou. Em Dois irmãos o casal é referido em relação à casa onde se organizavam festas que Omar frequentava e que foi o lugar do último baile de Yakub. No Relato, uma simples menção aos Benemou como vizinhos estrangeiros.

A repetição de personagens aumenta a impressão do espaço ficcional comum, reforçada também por outras ocorrências partilhadas como o mesmo cenário manauense e a temática retratando a vida de imigrantes libaneses.

8 No romance Dois irmãos, encontramos referências aos poemas de Laval que, depois da morte do poeta, continuam a existir na memória dos leitores: «Omar escreveu com tinta vermelha um verso de Laval, e por muito tempo as palavras permaneceram ali, legíveis e firmes, oferecidas à memória de um, talvez de muitos.»; (Hatoum, 2006: 143) «Seus poemas repousam por aí, em gavetas esquecidas ou na memória de ex-alunos.» (Hatoum, 2006: 145) 
A intertextualidade homo-autoral é particularmente marcante na coletânea de contos A cidade ilhada. Alguns dos contos apresentam relações intertextuais entre si e também com outras obras de Hatoum, mais precisamente com os romances Relato de um certo Oriente e Cinzas do Norte (2005). Assim, o conto «A natureza ri da cultura», publicado pela primeira vez em 1992, reintroduz o espaço do Relato de um certo Oriente (1989), junto com a mesma narradora e as personagens Emilie e o marido dela. Porém, aqui o enfoque é colocado nas personagens Armand Verne e Felix Delatour, amigos de Emilie, e no tema da impossibilidade da apropriação da cultura estrangeira.

Os contos «Varandas da Eva» e «Uma estrangeira da nossa rua» mantêm laços fortes de intertextualidade com o romance Cinzas do Norte. As obras têm em comum o espaço, o narrador e algumas personagens: tio Ranulfo, tia Ramira e, no caso do primeiro conto, o amigo Minotauro. Porém o foco é outro, agora centrado na juventude do próprio narrador. Também no conto «Uma estrangeira da nossa rua» é mencionada de passagem até mesmo a «madame Steinway», a pianista que tem um papel de destaque no conto «Dois tempos».

No romance Cinzas do Norte é mencionado também o local Varandas da Eva, ${ }^{9}$ espaço central do enredo do conto homônimo, com a atribuição de ele ser muito novo, o que implica um registro temporal diferente daquele tratado no conto.

Outro conto da coletânea que estabelece relação intertextual com Cinzas do Norte e também com «Varandas da Eva» é o conto «Dois tempos», onde, de novo, encontramos o mesmo narrador e as personagens tio Ranulfo e tia Ramira, como também uma menção ao «balneário noturno» Varandas da Eva. O foco é agora colocado na personagem da professora de canto, Tarazibula Boanerges, personagem que também é mencionada na novela Órfãos do Eldorado.

As referências às mesmas personagens da vida local e aos mesmo lugares, ou seja, ao mesmo espaço, às vezes vêm do fato de que nas suas obras Hatoum tematiza sobretudo a cidade de Manaus. Assim, no conto «Dois tempos» consta que Tarazibula era uma personagem importante da cidade: «Na minha cidade, ela era a protagonista do canto e do piano.» (Hatoum, 2009: 63) Desse modo, está traçada a ideia da criação de um espaço literário comum nas obras de Hatoum.

A intertextualidade homo-autoral hatoumiana também está relacionada com a criação de unidade entre as obras desse autor e com a criação de um efeito de

9 «Os assuntos eram variados e cruzados: reforma agrária, pesca de tambaqui, festa a bordo de um navio, o mais novo prostíbulo de Manaus, o Varandas da Eva.» (Hatoum, 2005: 22) 
realidade existente acima do nível compositivo de uma obra só. Nesse respeito concordamos com Aíla Sampaio (2010) quando ela, referindo-se à intertextualidade em $A$ cidade ilhada, diz que essa

intertextualidade homoautoral, ou seja, a utilização de recorrências espaciais, temáticas e de personagens, além de dar unidade ao projeto ficcional de Hatoum, dá ao leitor a impressão de que esses personagens têm existência real, não são meros seres de papel escondidos atrás das palavras quando se conclui a leitura da obra.

Acreditamos que a intertextualidade homo-autoral hatoumiana pode ser colocada em relação com a ideia da memória. Além de criar uma unidade ficcional através do espaço literário comum, a recorrência dos motivos e das personagens cria o efeito da existência de uma experiência coletiva; como essa experiência é muitas vezes referida através da lembrança, a nossa suposição é de que a consequência desse encontro poderia ser ligada à ideia da memória coletiva. Essa interpretação está pautada na criação de um espaço ficcional comum elaborado mnemonicamente a partir de perspectivas diferentes. Outro efeito criado pela intertextualidade homo-autoral que se refere à recorrência de narradores, seria a hipertrofia de lembranças e o estabelecimento dos narradores enquanto instâncias rememorativas. De fato, os narradores que se encontram repetidos em obras diferentes sempre se encontram no papel de instâncias que narram a partir de rememoração.

\section{Considerações finais}

No que concerne a relação entre as obras de Milton Hatoum e o conceito de memória (nos seus diferentes aspectos), os trabalhos, artigos científicos e dissertações são (cada vez mais) numerosos e as diferentes perspectivas usadas para abordar o assunto são desenvolvidas por parte de teóricas como Maria Zilda Ferreira Cury, Sylvia Telarolli e muitos outros. De fato, a memória parece ser o elemento central da poética hatoumiana - é o princípio propulsionador da narração onde as histórias são contadas através de reminiscências dos narradores (instâncias rememorativas) sobre histórias familiares (veja-se Bojić, 2014); memória é um dos temas e motivos recorrentes e a própria natureza do fenômeno encontra-se problematizada. Nesse sentido, acreditamos que, nos textos de Milton Hatoum, que retratam o fenómeno da memória por viéses literários, o diálogo intertextual parece levantar questões próprias sobre 
o papel da memória na literatura e também sobre a importância de obras literárias para a memória de indivíduos e coletividades.

Além de apontar, no nosso trabalho, para o modo como a relação entre intertextualidade e memória se encontra, nos textos de Hatoum, como que «internalizada» pela memória das personagens, esboçámos a biblioteca e o imaginário livresco presentes nas obras. O estudo dessa biblioteca intertextual ainda revelou que esta «memória da literatura» era essencial para a construção das obras de Hatoum.

Finalmente, completamos a nossa análise com os seguintes pensamentos. Referenciando-se continuadamente a textos anteriores, segundo Tiphaine Samoyault (2008: 10), «a literatura não para de lembrar»: «Entre retomada melancólica, em que ela se contempla no seu próprio espelho, e retomada subversiva ou lúdica, quando a criação se subordina à ultrapassagem daquilo que a precede, a literatura não para de lembrar e de conter um desejo idêntico, aquele mesmo da literatura.» A memória das narrativas de Milton Hatoum opera seguindo a dinâmica desses dois movimentos - por um lado, a recuperação de referências literárias que acrescenta a uma atmosfera melancólica já presente nas obras e, por outro, a re-escritura, o jogo e o apropriamento da tradição livresca.

\section{Bibliografia}

A Bíblia Sagrada (1968): Lisboa: Sociedade Bíblica de Portugal. (tradução de João Ferreira de Almeida).

Aguiar e Silva, V. M. de. (2011): Teoria da literatura. Coimbra: Almedina.

Bojić, M. (2014): «Memória como princípio da estruturação narrativa no romance Relato de um certo Oriente de Milton Hatoum», Studia romanica et anglica zagrabiensia. LIX.

Erll, A. (2011): Memory in culture. New York: Palgrave Macmillan.

Hatoum, M. (2005): Cinzas do Norte. São Paulo: Companhia das Letras.

Hatoum, M. (2006): Dois Irmãos. São Paulo: Companhia das Letras.

Hatoum, M. (2008): Relato de um certo Oriente. São Paulo: Companhia das Letras.

Hatoum, M. (2008): Órfãos do Eldorado. São Paulo: Companhia das Letras.

Hatoum, M. (2009): A cidade ilbada. São Paulo: Companhia das Letras.

Hatoum, M.: O arquiteto da memória. Entrevista concedida a Soraia Vilela: http://www.dw.com/pt/o-arquiteto-da-mem\%C $3 \% B_{3}$ ria/a-1355392 (o103-2016). 
Hatoum, M. Entrevista concedida a Aida Hanania: http://hottopos.com/ collat6/milton1.htm (20-03-2016).

Lachmann, R. (2004): «Cultural memory and the Role of Literature». European Review, 12, 165-178.

Lachmann, R. (2010): «Mnemonic and Intertextual Aspects of Literature». Em: Astrid Erll, Ansgar Nünning (eds.), A companion to cultural memory studies. Berlin: Walter de Gruyter.

Samoyault, T. (2008): A intertextualidade. São Paulo: Aderaldo \& Rothschild. (tradução de Sandra Nitrini)

Sampaio, A. (2010): «Personagens em trânsito, espaços subjetivos e intertextos em A cidade Ilhada, de Milton Hatoum», Revista Triplov de Artes, Religiões e Ciências, 5: http://novaserie.revista.triplov.com/numero5/aila_sampaio/ index.html (10-03-2016). 


\author{
Majda Bojić \\ University of Zagreb
}

\title{
Milton Hatoum, Intertextualiy and Memory of Literature
}

Keywords: Milton Hatoum, intertextuality, memory, recollection, memory of literature

Memory can be considered as the central element of the narrative aesthetics of contemporary Brazilian author Milton Hatoum. His works thematize the phenomenon and role of memory and also problematize the act of memory as well. Further, the narrative structure of Hatoum's fiction can be regarded as the result of recollection, necessary for the reconstruction of personal or family history. In this sense, we believe that the work of this writer comprises another phenomenon that can be viewed in relation to memory, thereby offering new lines of interpretation, that is intertextuality. As a literary device, intertextuality reveals itself as a universal in Hatoum's texts, in the form of relationships created not only with Brazilian and foreign textual references but also with the works of the author himself. The study of the intertextual dimension in the light of memory, reveals this equally important aspect of Hatoum's use of memory as a literary theme and device. 


\author{
Majda Bojić \\ Univerza v Zagrebu
}

\title{
Milton Hatoum, medbesedilnost in literarni spomin
}

Ključne besede: Milton Hatoum, medbesedilnost, spomin, spominjanje, literarni spomin

Spomini so lahko pojmovani kot osrednji element pripovedne estetike brazilskega pisatelja Miltona Hatouma. Njegova dela tematizirajo fenomen in vlogo spomina ter problematizirajo tako dejanja spominjanja kot procese reminiscence. Spomin tudi vzdržuje pripoved - pripovedna struktura fikcije Miltona Hatouma se udejanja kot rezultat spominjanja in je potrebna za rekonstrukcijo osebne ali družinske zgodbe. V tem smislu verjamemo, da delo tega amazonskega pisatelja vsebuje še en fenomen, ki bi ga lahko povezovali s spominjanjem in ki kot tak ponuja nove interpretacijske možnosti - medbesedilnost. Kot pripovedno sredstvo se ta v Hatoumovih besedilih razkriva kot stalnica, in sicer v obliki odnosov in razmerij, ustvarjenih ne le z referencami na brazilska in tuja besedila, pač pa tudi z referencami na avtorjeva lastna besedila. Raziskava medbesedilne dimenzije v luči spominjanja razkriva pomemben del mnemične mreže Miltona Hatouma. 